\section{Factors influencing the future of paediatric private practice in Malta}

\author{
Victor Grech,1 Charles Savona-Ventura,2 \\ Miriam Gatt, ${ }^{3}$ Simon Attard-Montalto 1 \\ 1Pediatric Department, \\ Mater Dei Hospital; \\ 2Dept of Obstetrics \& Gynaecology Mater \\ Dei Hospital; \\ 3Department of Health Information \\ and Research, Guardamangia, Malta
}

\begin{abstract}
In Malta, the health system is hybrid, with similarities to both UK system and the US system, where the National Health Service is supplemented by private practice. This is widely performed either as a primary job or as a supplement to a government salary. This article reviews unfavourable secular trends in Maltese fertility, births, marriages, separations, single parenthood and loans incurred after marriage, and relates them to (equally unfavourable in terms of private practice) escalating numbers of paediatricians working in private practice. Overall, future prospects appear bleak for private practice in this branch of medicine, with a dwindling patient pool being shared by an ever-increasing number of paediatricians. The only identifiable factor that may mitigate is the potential for more private health insurance uptake. This must be coupled with a movement to improve the perception of a substantial proportion of the public that facilities are poorer in the private health sector than in the NHS service. Since Malta is a developed, EU country, these results may (cautiously) be extrapolated to other, larger developed countries.
\end{abstract}

\section{Introduction}

Offspring are the consequence of natural biological laws and instincts that govern reproductive behaviour. The ascent of man, from hunter-gatheter barely surviving in a harsh savannah environment, to modern homo sapiens, has resulted in better environmental adaptation and mastery, and declining mortality rates, with survival of higher numbers of offspring to reproductive adulthood. ${ }^{1}$ In the absence of intelligent restraint, this would inevitably result in catastrophic Malthusian scenarios, wherein unchecked population growth always exceeds its minimum required resources, particularly its food supply, result- ing in starvation, disease and war.2,3

In developed countries, factors which ultimately establish the desired number of offspring are economic, cultural, political, historical and geographical. Indeed, in the West, children are often viewed as commodities, and the cost-benefit ratio of offspring can actually be calculated. Positive aspects of children include parental support, a direct contribution to the family's labour force, and an indirect contribution to family happiness. The negative aspects are the direct and indirect financial and temporal costs in raising children. 4,5

Malta is a developed country that has recently joined the European Union. The Maltese health service is a legacy of the occupation by the British Forces and is structured along similar lines to the British NHS. While the cost of living in Malta is not low, salaries remain relatively poor, and traditionally, most doctors (including specialists) perform varying degrees of private practice. Paediatricians are no exception and paediatric private practice consists, in the main, of primary care, i.e. routine visits, particularly in infancy, the administration of scheduled vaccines and the treatment of acute infectious illnesses such as coughs and colds, and gastroenteritis. There are two significant differences from the UK system. Firstly, patients may refer themselves to specialists in private practice, including paediatricians, and do not need to be referred by another doctor, such as a general practitioner. Secondly, fees charged by Maltese specialists are much lower than UK (or US) specialists, ranging from $€ 25$ (typically for a paediatrician), to around $€ 50$ in other specialities.

Only the minority of families (21\%) have private health insurance which is age-banded and does not usually incorporate individual underwriting cover. 6

Several social and demographic factors are likely to impact on this type of practice, and this paper identifies such trends and their likely implications. Since Malta is a developed country within the EU, these findings and conclusions may cautiously be extrapolated to other developed countries.

\section{Materials and Methods}

The catchment area for this study was Malta. Data was collected retrospectively from official publications generated by the Maltese National Statistics Office, ${ }^{3}$ and included annual live births (1970-2003), rates of single pregnancies (1960-2003) and total fertility rates (TFR: 1901-1995). The latter were obtained from census data which occurred approximately every 10 years. All practicing paediatricians were approached and asked when they commenced doing private practice (personal com-
Correspondence: Victor Grech, Paediatric Department, Mater Dei Hospital, Malta

E-mail: victor.e.grech@gov.mt

Key words: private practice, social class, single parent, live birth.

Received for publication: 9 December 2010. Accepted for publication: 18 April 2011.

This work is licensed under a Creative Commons Attribution 3.0 License (by-nc 3.0).

(C) Copyright V. Grech et al., 2011

Licensee PAGEPress, Italy

Pediatric Reports 2011; 3:e12

doi:10.4081/pr.2011.e12

munications), going as far back as 1970. Other relevant demographic and economic trends were also obtained from official publications generated by the Maltese National Statistics Office. ${ }^{3}$ Separations data were obtained directly from the Law Courts (Law Courts, personal communication).

\section{Results}

There has been a steady decline in the infant mortality rate (Figure 1), dipping down to levels expected of a developed country. There has also been a steady decline in the fertility rate (Figure 2) which has resulted in a sharp decline in the annual number of live

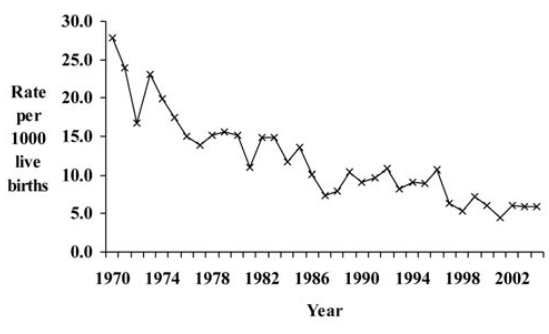

Figure 1. Infant mortality rate.

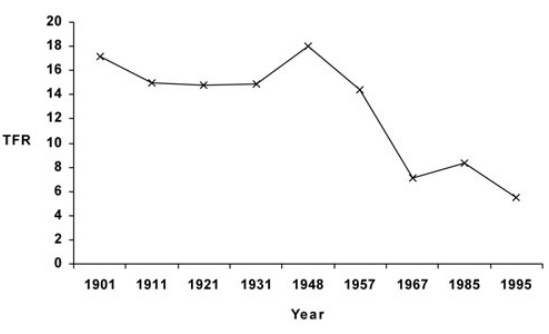

Figure 2. Total fertility rate. 
births (Figure 3). This contrasts sharply with a steep rise in the number of practicing paediatricians (Figure 3 ).

The decreasing birth rate is directly linked to an increase in income and loans, an increasing standard of education and a higher work activity rate amongst females.

Specifically: i) 6.6 babies were born for every $€ 2.3$ million earned in the form of disposable income in 1994, decreasing to 3.6 in 2002 ; ii) 32.4 babies were born for every million borrowed in the form of loans in 1994, decreasing to 7.7 in 2002 ; iii)11.0 babies were born for every female graduate in 1994, going down to 4.0 in 2002 ; iv) 0.15 babies were born for every 1,000 full-time female workers in 1994, going down to 0.10 in 2002.

Married couples are entering into ever increasing loans in order to finance the purchase of a living unit (Figure 4).

The proportion of pregnancies born out of wedlock (single mothers) has risen sharply (Figure 5), particularly over the past 15 years. For example, i) in 2004, there were an estimated 3310 single parent households, out of which 2500 were single mother households; ii) Single mother households amounted to 2.0 per cent of the total private household population and 10.2 per cent of households with a female head of household; iii) the average gross household income for household whose head is a single mother was estimated at $€ 3200$, compared with $€ 9200$ for other households;

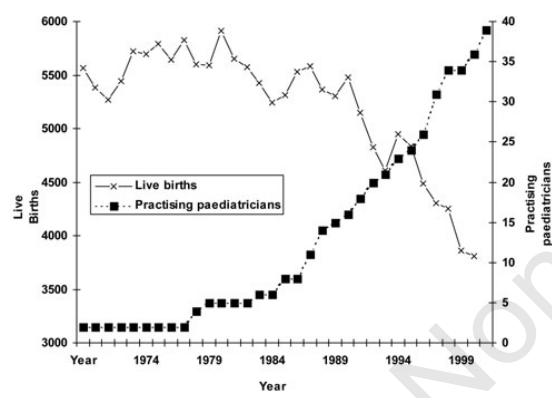

Figure 3. Annual number of live births (left $\mathrm{Y}$ axis) and number of practicing paediatricians (right $\mathrm{Y}$ axis).

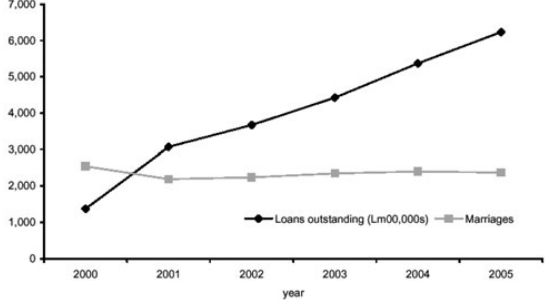

Figure 4. Loans outstanding and marriages. iv) this lower income is a result of lower activity rate within single mother households where only $25.2 \%$ were gainfully occupied, compared with 61.9 per cent for other households; v) additionally, $43.8 \%$ of persons living within such households were below the atrisk-of poverty rate, compared with $14.3 \%$ for other households.

Separations in Malta have also increased over the years for which data is available, and have plateaued at around 1000 applications for legal separation per annum (Table 1).

\section{Discussion}

At $\leq 5 / 1000$ live births, Malta has reached infant mortality levels expected of developed countries. This implies that children will survive and require routine medical services which may be availed of both via the NHS or via the private sector.

For a population to remain exactly constant in number, the total fertility rate must be 2.1 . This value is known as the replacement rate and assumes no immigration or emigration. Values higher than 2.1 result in population gains while values less than 2.1 eventually lead to population decline. Malta is clearly following in the heels of developed countries with plummeting fertility and birth rates. This will inevitably result in a smaller pool of patients

Table 1. Applications for marriage separations.

\begin{tabular}{lc}
\hline Year & Applications \\
\hline 1997 & 893 \\
1997 & 914 \\
\hline 1998 & 940 \\
1999 & 1067 \\
\hline 2000 & 1048 \\
2001 & 1135 \\
\hline 2002 & 1214 \\
2003 & 1244 \\
\hline 2004 & 1112 \\
2005 & 1026 \\
\hline 2006 & 998 \\
\hline
\end{tabular}

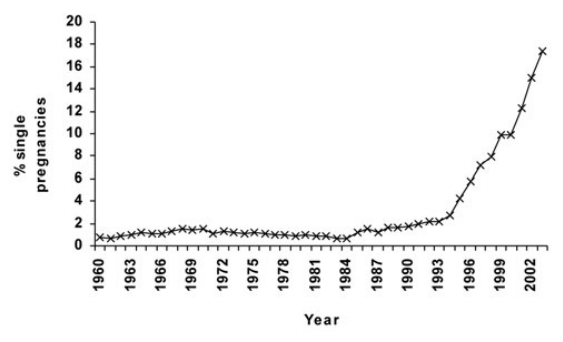

Figure 5. Percentage of pregnancies born out of wedlock. which must be shared with an ever increasing number of paediatricians who work primarily in the National Health Service with part time private practice.

Single parenthood may occur in the absence of marriage or as a consequence of breakdown of marriage. By their very nature and the socioeconomic circumstances that lead to single parents, such individuals are less likely to have partner support, are less likely to be affluent and are less likely to have private health insurance. Hence, single parents will be less likely to seek out paediatricians in private practice and are therefore more likely to seek out general practitioners in private practice, who charge a lower fee, or to seek medical attention from the free NHS health services available at GP manned Health Centres.

Married couples, on the other hand, are beset by spiraling property prices with high mortgage rates that severely erode into earnings and spending power, and may also seek the above alternative options.

Poor working conditions have led to several paediatricians leaving the National Health Service and devoting themselves fully to private practice. Due to the EU Working Hours directive the Health Service's Paediatric Department has had to employ more paediatric trainees, who will inevitably work part-time in private practice.

These factors imply that the pool of children who are taken to paediatricians in private practice will dwindle, while the pool of paediatricians is continually increasing.

And yet, doctors feel obliged to work in private practice in addition to NHS service due to poor salaries that currently are less than one quarter of their UK equivalent, with poor future prospects for significant salary improvement since the local authorities have spent almost $€ 700,000,000$ on the building of a new monolithic hospital which is expected to have proportionately monolithic running costs.

The only foreseeable mitigating factor for paediatric private practice is health insurance. Insured parents are more likely to seek paediatricians privately as fees would be borne by insuring companies. With a $21 \%$ health insurance uptake, the potential for improvement in this regard is high. However, a factor that mitigates against the uptake of health insurance is the escalating cost of annual insurance premium payments.

This is confirmed by a recent newspaper survey which showed that $66 \%$ of respondents cited expense as the reason for not having private insurance cover. Moreover, 28\% stated that they prefer state hospitals because they perceive better services available there. An additional $14 \%$ felt that it was unfair and therefore inappropriate, after paying taxes and national insurance contributions, to have to 
fork out more money for private medical insurance. ${ }^{7}$ Furthermore, the current credit crunch will inevitably erode into parents' spending power, who will therefore be less likely to see more expensive paediatricians over private general practitioners over free NHS health services available at GP manned Health Centres. Moreover, many parents extend their employer-subsidised health insurance to cover their children, so job layoffs will lead to a loss of the insured paediatric pool, and such parents (jobless and having lost health insurance coverage) are more likely to seek less expensive alternatives to paediatricians.

All of these factors, incidentally, will have a negative impact on local suppliers of medications, formula milk and vaccines - the less the parents' spending power and the smaller the paediatric pool, the smaller will be the demand for these goods.

Overall, future prospects for paediatric pri- vate practice in Malta appear bleak, and the only identifiable factors that may mitigate against this are the (now dubious with the onset of the credit crunch) potential for more private health insurance uptake coupled with a movement to improve the perception of facilities in private health care.

These findings may be extrapolated to most developed countries wherein birth rates are continually falling, the number of graduates is continually rising, and the disposable income is dropping.

\section{References}

1. Holliday R. Evolution of human longevity, population pressure and the origins of warfare. Biogerontology 2005;6:363-8.

2. Thomas Malthu. An Essay on the Principle of Population, as it Affects the Future Improvement of Society with Remarks on the Speculations of Mr. Godwin, M. Condorcet, and Other Writers. London: J. Johnson, 1798.

3. Central Office of Statistics. Demographic review for the Maltese Islands. Malta: Central Office of Statistics.

4. Leibenstein H. Socio-economic fertility theories and their relevance to population policy. International Labour Review 1974;109:443-57.

5. Tian X. Costs of children-benefit theory and population control. Chin J Popul Sci 1989;1:403-11.

6. Malta Department of Health Information. First National Health Interview Survey. Malta: Department of Health, 2003.

7. Times of Malta. Insurance Survey. Times of Malta. 2006 Nov 26. 